\title{
COกE).(OES
}

CIÊNCIA E TECNOLOGIA

\section{TEORIA ESPECIAL DA RELATIVIDADE: 100 ANOS APÓS, COMO ENSINÁ-LA SIGNIFICATIVAMENTE USANDO O CORDEL}

\author{
Ênio José Gondim Guimarães ${ }^{1}$, Francisco Augusto Silva Nobre ${ }^{1}$ \\ ${ }^{1}$ Secretaria da Educação do Ceará - SEDUC \\ ${ }^{2}$ Universidade Regional do Cariri - URCA \\ <enio12fisica@gmail.com>< <augusto.nobre@urca.br> \\ DOI: https://doi.org/10.21439/conexoes.v13i4.1858
}

\begin{abstract}
Resumo. Neste trabalho mostramos que o folheto de cordel pode ser usado como ferramenta de ensinoaprendizagem da Teoria Especial da Relatividade (TER), bem como, proporcionar aprendizagem significativa a partir de uma sequência de ensino. A aprendizagem significativa na educação e o saber produzido historicamente, são referenciados pela aprendizagem significativa (AUSUBEL, 2003) e com a pedagogia histórico-crítica (SAVIANI 2003). Para tal, aplicamos o cordel numa turma de 30 alunos (as) do ensino médio, numa escola pública de Fortaleza. Com o uso do folheto de cordel e a sequência de ensino proposta, acarretou-se, interesse nos estudantes pela Teoria Especial da Relatividade e geraram-se indicativos de aprendizagem significativa.
\end{abstract}

Palavras-chaves: Folheto de cordel. Ensino da Relatividade. Sequência de ensino.

\begin{abstract}
In this paper we show that the cordel leaflet can be used as a teaching and learning tool of the Special Theory of Relativity. Likemanner, it can provide meaningful learning from a sequence of teaching. Meaningful learning in Education and historically produced knowledge are referenced by meaningful learning (AUSUBEL, 2003) and historical-critical Pedagogy (SAVIANI, 2003). This way, we applied the cordel in a class of 30 high-school students in a public school in Fortaleza. With the use of the cordel leaflet and the proposed teaching sequence, it has led to students' interest in the Special Theory of Relativity and indicative of meaningful learning were generated.
\end{abstract}

Keywords: Cordel leaflet. Special Teaching of Relativity. Sequence of Teaching.

\section{INTRODUÇÃO}

Este trabalho surgiu após as reflexões no Mestrado Nacional Profissional em Ensino de Física (MNPEF). A partir delas, percebemos que era possível ensinar Física Atômica e Nuclear e a Teoria Especial da Relatividade (TER) utilizando o folheto de cordel. Desta forma, elaborarmos um cordel, ferramenta para facilitar ensinarmos ao educando os princípios, postulados e Teoria Especial da Relatividade significativamente, que nos faça sairmos dos moldes tradicionais do ensino, conforme Ausubel (2003), e possibilite um estudo crítico da teoria, de acordo com Saviani (2003).

Para isso, o folheto de cordel elaborado possibilitou ensinarmos ao educando a Teoria Especial da Relatividade como uma ferramenta simples e eficaz, e nos tirou da zona de conforto tradicional de ensinar os conteúdos. A esse respeito, os Parâmetros Curriculares Nacionais - PCN (2015), dizem que as estratégias a serem desenvolvidas em sala de aula devem reforçar e considerar o mundo em que o discente está inserido e não só reconhecer o seu cotidiano como objeto de estudo, mas em todas as dimensões culturais, sociais e tecnológicas onde vive. Essa premissa valida as estratégias desenvolvidas nessa pesquisa, haja vista aplicar o cordel como ferramenta.

Utilizarmos o folheto de cordel para o ensino da (TER), apropriando-nos deste como ferramenta de ensino, e proporcionarmos uma forma mais lúdica de aprender essa teoria que muitas vezes não é vista pelos discentes. Por isso, torna-se relevante, visto que a escola é a principal fonte de conhecimento formal com 
a qual o discente da educação básica terá contato. Acreditamos também que a introdução de tal conteúdo com o cordel no currículo da escola pode amenizar as dificuldades dos(as) alunos (as) sobre os fenômenos da natureza e melhora o raciocínio cognitivo prévio.

Usar o folheto de cordel para o ensino da (TER) é conciliar a ciência física e a poesia. O cordel, apropriando-se deste como metodologia de ensino. Pensando assim, o objeto de estudo deste trabalho é ensinar significativamente a (TER) usando o folheto de cordel como recurso docente juntamente com uma sequência de ensino.

Para tanto, o professor/pesquisador e poeta Guimarães. E.J.G elaborou o folheto de cordel. Antes da construção do folheto, nos apropriamos e estudamos minuciosamente as partes que compõem um poema: as rimas, a métrica e a estrofaçã $\emptyset^{1}$ Assim, para iniciarmos a escrita do folheto, que têm como texto de referência o livro Física Conceitual, de Hewitt (2015), fizemos o fichamento do capítulo e selecionamos os conceitos que utilizamos para elaboração dos versos.

Buscamos elucidar o mundo da (TER) (postulados, princípios, equações, espaço-tempo, dilatação temporal, contração do tempo e do comprimento, etc.) com a sequência de ensino e o folheto de cordel dentro de uma visão histórico-crítica e visando a aprendizagem significativa. Nessa perspectiva, o educando deve saber representar e comunicar-se com a linguagem de Física e os elementos de sua representação simbólica que lhe foram apresentados. Em suas investigações, interpretações e compreensões, deve conhecer a Física presente nos fenômenos que vão ser evidenciados no folheto de cordel.

\section{FUNDAMENTAÇÃo}

A nossa vivência no mundo escolar nos diz que a forma de ensinar centrada no (a) professor (a) não leva o estudante a uma aprendizagem significativa nem crítica sobre o mundo que o cerca. Portanto, cabe ao (a) professor (a) escolher uma metodologia adequada ao conteúdo que vai ensinar, de acordo com sua formação e conhecimento. Assim, romper esse paradigma é ter primeiro que reavaliar as práticas docentes e implementar o uso de novas metodologias didáticas em sala de aula.

\footnotetext{
${ }^{1}$ Estrofação: a divisão de uma poesia/cordel em estrofes. De acordo com o número de versos, as estrofes no cordel mais usadas são: Quarteto: quatro versos; Sextilha: seis versos; Septilha: sete versos e Décima: dez versos. Disponível em: $<$ http://pensandoemliteratura.webnode.com.br/news/introdu\%C3\%A7 \% $3 \%$ A $30 \% 20$ ao\%20estudo\%20da\%20poesia\%20camoniana/> Acesso em: 11 set. 2017.
}

$\mathrm{Na}$ tentativa de reverter este quadro e oferecer aos discentes uma aprendizagem significativa, conforme Ausubel (2003), e um estudo crítico dos princípios, conceitos e postulados da (TER), de acordo com Saviani (2003), elaboramos um cordel e uma sequência de ensino que possibilitaram ensinar a teoria de forma mais estimulante, possibilitando aos discentes mudarem seu ponto de vista com relação à (TER).

Com isso, passaram a ver a (TER) como algo desafiador e empolgante, rompendo as barreiras e as dificuldades encontradas na apreensão dos princípios e postulados desta teoria. Assim, os objetivos de uma aprendizagem significativa, crítica, interdisciplinar e contextualizada, que proporcionem uma participação efetiva dos discentes no processo ensino-aprendizagem, é um dos caminhos para amenizar as lacunas do ensino centrado no (a) professor (a).

Pensando nisso, propomos a interação multilateral entre professor (a) e alunos (as), tendo como referencial teórico a Pedagogia Histórico-crítica de Saviani (2003) e a Aprendizagem Significativa de Ausubel (2003), pois a estruturação das aulas pautadas na teoriaprática-teoria, produz reflexos positivos na praxe de sala de aula, uma vez que permite contextualizar o ensino e a aprendizagem em situações experimentadas ou não no mundo, o que possibilita aproximar os educandos dos conhecimentos e fenômenos físicos.

Assim, para averiguar o desvelar da (TER), o educando deve saber representar e comunicar-se com a linguagem da Física e os elementos de sua representação simbólica que lhe foram apresentados, bem como em suas investigações, interpretações e compreensões, deve conhecer a Física presente no mundo e nos fenômenos que vão ser evidenciados no folheto de cordel.

Pensando nisso, autores como Zanetic (1990), Moreira, Massarani e Almeida (2005) e Piassi (2007) indicam a importância de fornecer cultura (música, teatro, poesia, etc) ao processo educativo escolar, como possibilidade de interpretar o mundo.

Para esse fim, aulas de Física interdisciplinar, enriquecidas com cordel, promove o desenvolvimento do raciocínio lógico, um diálogo em duas vias com a sociedade, as diferenças e (as)simetrias entre ciências e artes e a apreensão do mundo real a partir dos princípios e postulados apresentados da (TER). Para tal, propomos a utilização do folheto de cordel com uma sequência de ensino, a fim de que seja possível desenvolver esses aspectos nos discentes.

Logo, utilizarmos os folhetos de cordel como ferramenta didática no processo ensino-aprendizagem em Física. Não é, como bem nos lembra Nobre (2015. 
p. 12), para que este seja preservado como relíquia da tradição nordestina ou algo pitoresco, mas para torná-lo uma ferramenta de ensino e de conhecimento científico, bem como, fazer com que o (a) professor (a) repense o seu ensinar e que o mesmo possa ir além dos muros do livro-texto. Dessa forma, propomos o ensino dos princípios, dos postulados e da Teoria Especial da Relatividade utilizando-se o cordel para trazer o foco da ciência, da poesia, da rima e do folheto para o ensino.

Como vemos, a Física deve ser entendida como uma ciência que está inserida na sociedade. Para que seja conhecida e desvelada, segundo Saviani (2003), é necessário a escola assegurar o acesso ao saber historicamente construído pela humanidade, e, para Ausubel (2003), uma aprendizagem significativa aos alunos. Isso não significa abandonar os conteúdos ou vê-los de forma simplificada e superficial; os conteúdos foram explorados com rigor, escolhidos criteriosamente e tiveram um tratamento didático adequado, a fim de que não representassem uma enxurrada de fórmulas e informações desarticuladas e desvinculadas da vida do discente e da sociedade.

Portanto, é necessário ir além do repassar e transmitir conhecimento. Deve-se compreender o que é o ensino para garantir a investigação e o interesse do estudante em aprender. É nessa perspectiva que entra o folheto de cordel no ensino dos conhecimentos de Física, para contribuir com a construção de competências e habilidades, com atitude crítica dos atores envolvidos nessa relação diante dos fatos e acontecimentos ocorridos diariamente, relacionados à Ciência e à tecnologia.

Além do mais, a linguagem, para Ausubel (2003), é um importante facilitador da aprendizagem e significativa em consequência de sua recepção proporcionar a descoberta, e que a mesma aumenta a manipulação dos conceitos, tornando-os mais precisos e ficando mais acessíveis a sua assimilação. Portanto, cumpre seu papel integral que é o da aprendizagem e não só de uma ação acumulativa de informações. Nessa perspectiva, o folheto de cordel, além de facilitar o entendimento, fará a articulação entre o conhecimento prévio do (a) aluno (a) com a informação científica que se pretende adquirir.

\section{METODOLOGIA APLICADA}

Para escrevermos o folheto, utilizamos como fonte teórica primária, o livro Física Conceitual de Hewitt (2015). Para isso, foi feito o fichamento do capítulo que trata da Teoria Especial da Relatividade. Sendo que este conteúdo foi efetivamente utilizado na aplicação em sala de aula, na intervenção pedagógica.
Figura 1: Capa do Cordel - Teoria da Relatividade
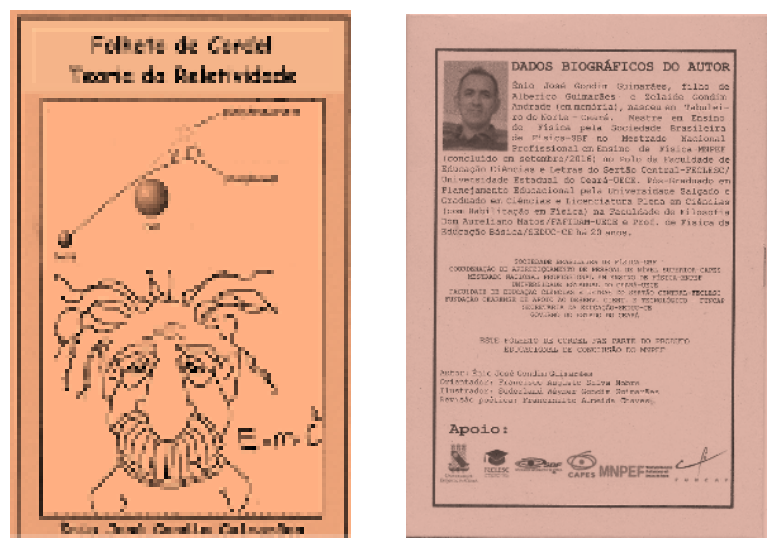

\subsection{A Sequência Didática ou Sequência de Ensino}

Segundo Iliovitz, (2016, apud DOLZ, NOVERRAZ E SCHNEUWLY, 2004, p. 82), sequência didática é "um conjunto de atividades escolares organizadas, de maneira sistemática, em torno de um gênero textual oral ou escrito". De acordo com Thiago, (2016, apud SOUZA, 2013, p. 50), sequência de ensino é "a organização de um determinado saber, em etapas sequenciais, como forma de produzir um conhecimento específico". Desse modo, podemos dizer que a diferença entre as duas são: a primeira deve ser usada para organizar e orientar produções de um gênero textual oral ou escrito enquanto a segunda é utilizada para produzir um conhecimento específico de um ensino, organizado em etapas sequenciais.

A sequência de ensino utilizada na aplicação do folheto de cordel, é inspirada na sequência de ensino de Nobre (2015 ${ }^{2}$ e na Sequência FEDATHI, de Borges Neto (2013 ${ }^{3}$ Na Tabela 1 descrevemos um resumo da ação pedagógica utilizada para a aplicação da sequência de ensino proposta com o uso do folheto da Figura 1

A sequência de ensino utilizada em sala de aula, no dia a dia, para o uso do folheto de cordel, foi desenvolvida de acordo com as seguintes etapas:

\footnotetext{
${ }^{2}$ As etapas da sequência: $1^{\mathrm{a}}$ - Apresentar o folheto. $2^{\mathrm{a}}$ - Solicitar um voluntário para declamar o folheto. $3^{\mathrm{a}}$ - Discutir e interpretar o texto do folheto em grupos de 2 (dois) a 4 (quatro) estudantes e a $4^{\mathrm{a}}$ Debater/discutir sobre o conteúdo científico do folheto em um grupo formado por todos da etapa anterior.

${ }^{3}$ As etapas da sequência FEDATHI: $1^{\mathrm{a}}$ - Tomada de posição: apresentação do problema. $2^{\mathrm{a}}$ - Maturação: compreensão e identificação das variáveis envolvidas no problema. $3^{\mathrm{a}}$ - Solução: representação e organização de esquemas/modelos que visem à solução do problema. $4^{\mathrm{a}}$ - Prova: apresentação e formalização do modelo a ser ensinado.
} 


\begin{tabular}{|c|c|}
\hline SEMANA & INTERVENÇÃO PEDAGÓGICA \\
\hline $1^{\mathrm{a}}$ & $\begin{array}{r}\text { Explicação sobre a metodologia e avaliação diagnóstica (do cordel, do conteúdo do cordel) } \\
1^{\mathrm{a}} \text { etapa da sequência de ensino proposta. }\end{array}$ \\
\hline $2^{\mathrm{a}}$ & Aplicação do folheto (com a sequência de ensino, $2^{\mathrm{a}}$ e $3^{\mathrm{a}}$ etapas). \\
\hline $3^{\mathrm{a}}$ & Continuação do folheto (aplicação da $4^{\mathrm{a}}$ etapa da sequência de ensino). \\
\hline $4^{\mathrm{a}}$ & Exercícios de aprendizagem (aplicação da $5^{\mathrm{a}}$ etapa da sequência de ensino). \\
\hline $5^{\mathrm{a}}$ & Verificação de aprendizagem. (aplicação da $6^{\mathrm{a}}$ etapa da sequência de ensino). \\
\hline $6^{\mathrm{a}}$ & As entrevistas e a avaliação diagnóstica (sobre o cordel). \\
\hline
\end{tabular}

1. Socialização: momento em que iniciamos a aula fazendo uma explicação geral sobre a importância, o que, o porquê da pesquisa, e em seguida aplicamos uma avaliação diagnóstica que versava sobre a utilização ou não do cordel em sala de aula e sobre a Teoria Especial da Relatividade. Questionamos se a metodologia seria importante para o ensino de Física e se a conheciam. Se queriam participar de uma aula de Física com cordel para estudar a teoria da relatividade e se gostariam que o cordel fosse usado com mais frequência.

2. Tomada de posição: nessa etapa iniciamos a aula dividindo a turma e distribuímos um folheto para cada dois discentes. Em seguida, com ele em mãos e projetado na parede da sala, falamos um pouco do poeta/professor, dos princípios, teoria e postulados que iriam ser abordados e dos aspectos gráficos. Dando prosseguimento, solicitamos um voluntário para declamar o folheto para que pudessem identificar e compreender os postulados, teoria e os fenômenos físicos. O objetivo neste momento é estabelecer uma visão geral dos conceitos abordados, como também exercitar a interdisciplinaridade, com a leitura e a declamação.

A declamação é essencial neste processo, pois os antigos poetas, ainda na Europa, como também no interior do Nordeste, usavam a declamação, e ainda usam como processo de melhor assimilação da mensagem que queiram repassar. Logo, não faz sentido o uso dos folhetos se estes não forem declamados.

3. Maturação: nessa etapa, com os discentes em duplas, pedimos que cada uma delas fizesse novamente uma leitura declamada para depois discutir e interpretar o texto do folheto. É nesse momento que se exploram nos (as) alunos (as) os seus conhecimentos prévios e como eles podem fazer a relação do conteúdo exposto no folheto com o seu cotidiano social, político e ambiental. Nessa etapa, o (a) professor (a) deve deixar os (as) alunos (as) descobrirem por eles mesmos os conceitos da teoria posta no folheto.

4. Solução: onde os discentes coletivamente apresentaram e discutiram os modelos dos conteúdos científicos do folheto. Nesse instante, o (a) professor (a) usa o momento para fazer analogia com os modelos científicos preexistentes e, assim, formaliza o conhecimento que está sendo construído e sistematiza, explora os erros (não como uma forma punitiva, mas como função positiva na solidificação do conhecimento e do saber) e acertos dos estudantes.

5. Consolidação dos conceitos: nessa fase, propusemos aos discentes que solucionassem alguns problemas, para percebermos se os conteúdos científicos do folheto tinham sido compreendidos. Esse é o momento para o (a) professor (a) averiguar se eles identificaram e representaram os modelos nos problemas.

6. Comprovação ou prova: é a fase final que utilizamos para realizarmos uma verificação de aprendizagem para analisarmos como eles chegaram à solução. Por que não alcançaram? Esse momento foi usado para observarmos se a representação e formalização do modelo ensinado foi apreendido.

\section{RESULTADOS E DISCUSSÃO}

No primeiro momento em sala de aula, iniciamos explicando como seria desenvolvido o trabalho. Fizemos um breve relato enumerando os passos que iríamos dar até concluirmos a intervenção pedagógica. Entre eles destacamos o número de aulas (semanas) que utilizaríamos e quais os conteúdos do folheto, como descrito na Tabela 1 . 
Além do mais, não é exagero reforçar que, os teóricos Saviani (2003), Ausubel (2003), em quem nos respaldamos para compreender o conceito de aprendizagem, frisam que o (a) professor (a) deve partir do conhecimento prévio do (a) aluno (a) para facilitar a compreensão e assimilação dos novos conceitos a serem apresentados e que os mesmos podem apreender os modelos gerais dos conceitos e desenvolver seu raciocínio lógico-dedutivo a fim de resolver os problemas do dia a dia e desenvolver o seu conhecimento científico.

Constatamos que embora não tivessem aproximação com a (TER) nem com o folheto de cordel em suas aulas, os discentes já conheciam esse gênero literário, o que garantiu uma maior afinidade com o folheto de cordel no ensino da Teoria Especial da Relatividade. Durante a aplicação percebemos, nas falas dos (as) alunos (as) que o aprendizado da Física estava diretamente relacionado à forma tradicional de ensino. Os mesmos não imaginavam a possibilidade de aprender os princípios, conceitos e postulados da (TER) com cordel.

\subsection{O Saber Preexistente do (a) Aluno (a)}

Assim, na averiguação sobre o conhecimento prévio, na primeira semana de aula, explicamos aos discentes que utilizaríamos o cordel para ensinar a Teoria Especial da Relatividade e fizemos algumas indagações, tais como: "Vocês conhecem o cordel?", "Alguém já manuseou um cordel?", "Estudaram com o cordel assuntos de alguma disciplina?", "Sabem o que é a Teoria Especial da Relatividade?", "Alguém leu ou ouviu algo sobre espaço-tempo e dilatação temporal?", "Têm conhecimento do que é contração do comprimento?", "Conhecem simultaneidade de eventos?", "Viram ou têm noção de sistema de referência?"

O intuito desses questionamentos iniciais era verificar o nível de conhecimento e socialização dos (as) alunos (as) com o cordel e com a (TER). Como veremos, essa ferramenta e seu potencial interdisciplinar não são habitualmente usados e a (TER) é pouco ou quase não é ensinada nas aulas do ensino do médio. Vejamos alguns resultados que foram obtidos na avaliação diagnóstica, com os (as) 30 alunos (as) do $2^{\circ}$ ano do ensino médio:

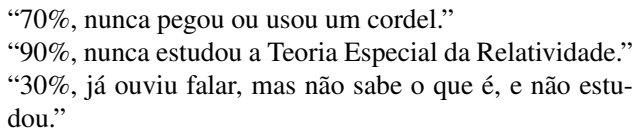

Identificamos que embora não utilizassem o folheto de cordel, os (as) alunos (as) o conheciam, o que para nós facilitou seu uso no ensino da (TER), pois nunca lhes foi proporcionado. Porém, com relação à (TER), ficou claro que o conhecimento prévio do assunto é quase inexistente.

Com relação à importância da utilização do cordel nas aulas de Física, nos dados colhidos dos questionários, os (as) alunos (as) se mostraram entusiasmados com a possibilidade, mostrando que estavam abertos à experiência. A empolgação com a ferramenta e com o assunto se consolidou, pois quando interrogados se desejariam que essa metodologia fosse utilizada com maior frequência, a turma quase toda foi favorável, estando apenas três alunos (as) em desacordo com a maioria (de um total de 30). Alguns se posicionaram:

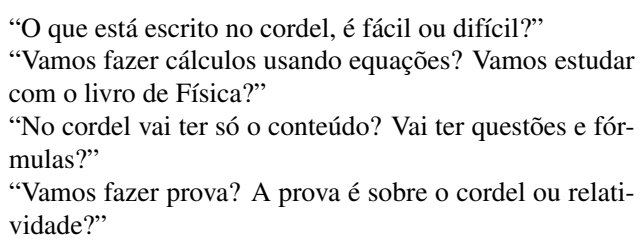

Percebemos nas falas dos (as) alunos (as) que o aprendizado da física estava diretamente relacionado à forma tradicional de ensino. Os mesmos não imaginavam a possibilidade de aprender a Teoria Especial da Relatividade com o cordel.

\subsection{O Saber Que Emergiu Depois da Aplicação do Cordel}

Passemos agora a analisar a avaliação diagnóstica levando em consideração o aspecto didático e sua funcionalidade como ferramenta de ensino, após aplicarmos o folheto da (TER).

A esta etapa do ciclo da pesquisa-ação chamamos de reflexão, na sequência de ensino; ainda faz parte da tomada de posição. Os (as) alunos (as), após terem contato com a ferramenta foram levados a refletir sobre a utilização do cordel:

\footnotetext{
"Para 90\% dos (as) alunos (as), a aula foi muito diferente e legal."

" $100 \%$ da turma afirmou que é a primeira vez que viu esse conteúdo em cordel."

"Considerando se foi mais fácil, $95 \%$ confirmaram que sim, e escreveram minha nota é 1000 (mil).”
}

Com relação à aprendizagem, os discentes foram unânimes em afirmar que o folheto de cordel havia possibilitado uma maior compreensão do conteúdo. Afirmaram que seria importante utilizar essa metodologia com mais frequência nas aulas de Física. Essas questões nos levam a afirmar que a ferramenta teve uma ampla aceitação pela turma. As falas dos (as) alunos (as) demonstram bem esse fato: 
"Como a aula foi dada, ajudou a entender e aprender".

"Eu aprendi coisas que não sabia, foi gostoso estudar com o cordel".

"Para mim facilitou aprender, deveriam usar ele e outras formas para ensinar".

"A linguagem é simples, compreendi melhor".

Como vemos, ao serem indagados novamente da importância de uma aula de Física em cordel, diferentemente da resposta na avaliação anterior, os (as) alunos (as) apresentaram em suas respostas muita credibilidade na ferramenta.

A credibilidade apresentada pelos (as) alunos (as) está diretamente relacionada à aprendizagem dos conteúdos trabalhados no cordel. Este fato fica evidente nas perguntas posteriores. Os discentes afirmaram que o interesse e compreensão da (TER), após a aula, tinha aumentado, diferentemente do questionário anterior, no que afirmaram que o cordel em nada mudaria seu interesse. Todos afirmaram na pergunta seguinte que haviam compreendido o conteúdo apresentado, como pode ser verificado nas respostas das entrevistas transcritas abaixo:

"É melhor de aprender os conteúdos, estão mais simples e mais claro [sic] de ver e estudar".

"Ajudou entender esse conteúdo que nunca vimos, ficou fácil aprender".

Assim como foi dito por Nobre (2015), e evidenciado nas falas dos (as) alunos (as), o folheto de cordel desde sua origem com a oralidade dos cantadores e também nos folhetos no Nordeste do Brasil, funcionou como meio de informação e divulgação de conhecimento, cumprindo o papel de informar, de ensinar.

Ao serem levados novamente a apresentar suas impressões sobre a aula, os (as) alunos (as) afirmaram que a aula era divertida, interessante, e que tinham compreendido melhor o conteúdo. Com relação a avaliação anterior, os (as) alunos (as) ampliaram seu olhar sobre a aula, caracterizando-a de forma positiva e relacionada ao conteúdo. Vejamos o que alguns escreveram,

\footnotetext{
"Foi melhor estudar Física assim".

"Os conteúdos chatos da Física em cordel, ficou [sic] direto e claro".

"Muito diferente, interessante e legal aprender assim"

"Com o cordel ficou muito simples e fácil compreender o conteúdo".
}

Esta última fala expressa o que denominamos de ampliação do conhecimento que, segundo Saviani (2003), são as mudanças sofridas com as experiências. Dessa forma, trabalhar a (TER) em cordel, possibilitou um aprendizado permanente por estar diretamente relacionado a uma linguagem simples e ao cotidiano do (a) aluno (a). Ou seja, "o saber que diretamente interessa à educação é aquele que emerge como resultado do processo de aprendizagem, como resultado do trabalho educativo (SAVIANI, 2003)".

Na maturação, os discentes foram levados ao trabalho em grupo, a fim de fazerem nova leitura e interpretação dos conceitos trabalhados no cordel. Frente aos questionamentos feitos pelo pesquisador/professor, de grupo em grupo, os (as) alunos (as) passaram à incorporação dos conceitos científicos, buscando romper com o senso comum, pois, os questionamentos, além de promoverem o desenvolvimento intelectual dos (as) alunos (as), possibilitaram ao professor/pesquisador certificar se estes estão acompanhando o avanço dos conteúdos ensinados.

Apropriando-se do cordel, os discentes identificaram a consequência do segundo postulado da relatividade, caracterizando e formulando verbalmente, como por exemplo, a simultaneidade, que nos livros didáticos muitas vezes não é vista e no senso comum é de difícil percepção. No cordel, a inclusão desse postulado foi facilmente identificada. Os discentes compartilharam entre eles a percepção de que a simultaneidade de dois eventos só ocorre se eles acontecem no mesmo instante de tempo, relacionando diretamente ao exposto no cordel.

Os questionamentos surgidos entre os (as) alunos (as) foram socializados através dos desenhos contidos no cordel. Na recorrência de dúvidas já trabalhadas, induzimos os (as) alunos (as) a refazerem a metodologia já realizada, leitura e reflexão em grupo, contando também com a ajuda do pesquisador/professor como mediador na formulação de perguntas esclarecedoras, estimuladoras e orientadoras.

$\mathrm{Na}$ observação, no desenvolvimento do raciocínio dos (as) alunos (as), percebemos que alguns tinham maior dificuldade em elaborar os princípios, conceitos e postulados da (TER). Mas visualizamos que o trabalho em grupo colaborou para a melhoria desse aspecto. A percepção de um (a) aluno (a) instigava a compreensão do outro.

Na fase de solução da sequência de ensino proposta, partimos para a troca de ideias e opiniões. Para facilitar a compreensão do grupo, visto que o tempo para a maturação foi breve, não suficiente à compreensão de todos (as) os (as) alunos (as), o pesquisador/professor pôs em discussão algumas estrofes, em especial aquelas que possuíam os princípios, conceitos e os postulados pouco explorados ou não nos livros didáticos, sempre indagando aos (as) alunos (as) sobre suas percepções. Após esse momento vejamos a que constatações os (as) 
alunos (as) chegaram:

"Estudar com o cordel foi muito bom, claro e simples".

"Nunca estudamos a relatividade, não chega a ser vista e explicada no livro".

"Achei que eventos simultâneos num sistema de referência, seria simultâneo a qualquer outro que se move".

Destas falas, nos concentramos no que está diretamente relacionado à aprendizagem. Em nossa leitura, o folheto de cordel, por ter uma linguagem simples, clara e objetiva, e acima de tudo, rimada, possibilitou uma maior compreensão, com uma menor dispersão - ao contrário do livros didáticos, que trazem muitas informações, muitos textos, fazendo com que os (as) alunos (as) não se detenham nos pontos principais dos conceitos.

Por fim, chegamos à última etapa da sequência: a prova. Assim, trabalhamos com os (as) alunos (as) o modelo geral, o que para o currículo prescrito é a incorporação das competências e habilidades dos conceitos estudados no cordel.

Para esta fase, foi trabalhada uma avaliação diagnóstica. Dentre as perguntas destacamos: "O cordel contribuiu para a aprendizagem dos conteúdos apresentados?", "As aulas da (TER) em cordel melhoraram sua compreensão dos princípios, teoria e postulados estudados?". Vejamos algumas respostas dos (as) alunos (as):

\footnotetext{
"Sim, compreendi melhor o que estudei".

"Sim, fica mais fácil estudar assim. A rima, compreendo melhor".

"Sim, entendi o conteúdo. Foi mais simples e direto".

"É melhor assim, com certeza; a rima facilita e é simples".
}

Ficou claro para nós que o folheto de cordel viabilizou a aproximação maior dos conhecimentos da Física trabalhados nas aulas.

No que diz respeito aos conhecimentos específicos da Relatividade, quando tratamos dos postulados da teoria e da simultaneidade, a turma compreendeu e entendeu que os referenciais são importantes para observar e medir os movimentos. Porém, o que observamos em alguns (as) alunos (as) foi uma dificuldade em assimilar e fazer a construção geral dos conceitos.

$\mathrm{Na}$ questão onde tratamos das leis da natureza, os (as) alunos (as) optaram pela resposta correta, pois na estrofe que tratava desse postulado, eles perceberam claramente que elas são as mesmas, desde que os sistemas se movam com velocidade uniforme, mostrando que o conhecimento científico expresso nos versos fizeram com que o folheto de cordel cumprisse seu papel como ferramenta de ensino.
Ao tratarmos da velocidade da luz, antes "um terço" da turma tinha escolhido o valor $3 \cdot 10^{5} \mathrm{~km} / \mathrm{s}$ ou 3 . $10^{8} \mathrm{~m} / \mathrm{s}$; porém, depois do aprofundamento, das discussões e da objetividade do folheto, $85 \%$ dos (as) alunos (as) marcou a alternativa correspondente ao valor. Para os $15 \%$ restante, verificamos a dificuldade de eles trabalharem com as operações e propriedades da potenciação. Com relação à propagação da luz no espaço livre, constatamos que o conhecimento prévio inexistia. Já na questão que tratou de simultaneidade, ocorreu que, quando recorreram ao conceito, este foi compreendido e ancorado em eventos diferentes. Com relação à aprendizagem, os (as) alunos (as) afirmaram que seria importante utilizar essa metodologia com frequência nas aulas de Física. Os (as) alunos (as) ratificaram que o cordel possibilitou mais interesse pela disciplina.

Na maturação, os (as) alunos (as) passam à incorporação dos conceitos científicos, rompendo com o senso comum, pois, os questionamentos, além de promoverem o desenvolvimento intelectual dos (as) alunos (as), possibilitaram ao professor/pesquisador certificar se estes estão acompanhando o avanço dos conteúdos ensinados.

Apropriando-se do cordel, os (as) alunos (as) identificaram os princípios e postulados da Teoria Especial da Relatividade, caracterizando e formulando verbalmente alguns deles como por exemplo, o Princípio da Equivalência, Espaço-tempo, Dilatação Temporal e Contração do Comprimento, que no livro didático nem sempre são tratados e no senso comum são difíceis de serem analisados e observados. No cordel, a inclusão deles foi facilmente observada. Os (as) alunos (as) compartilharam entre eles a percepção de que no Princípio da Equivalência as observações são indistinguíveis se forem realizadas em um sistema de referência acelerado. Já o espaço-tempo é lugar, "continuum tetradimensional", onde todas as coisas existem e que as 4 (quatros) coordenadas são as 3 (três) dimensões juntamente com o tempo, assimilado e relacionado diretamente ao exposto no cordel.

\section{CONCLUSÕES}

Refletindo sobre a análise dos dados, o produto educacional, a sequência e a condução do processo como um todo, desde a apresentação aos discentes até a avaliação da aprendizagem, podemos assegurar que o folheto de cordel e a sequência de ensino se configuraram como ferramenta viável de ensino-aprendizagem dos conceitos de Física.

Concluímos que o folheto aplicado, bem como a sequência, tiveram seus objetivos atingidos, pois os re- 
sultados conseguidos nas avaliações de aprendizagem e nas falas dos estudantes revelam que houve uma aprendizagem potencialmente significativa dos conceitos, princípios e postulados relacionados à Teoria Especial da Relatividade.

A pesquisa envolveu processos que não poderiam ser quantificados retratando a realidade dos fatos $\mathrm{e}$ acontecimentos de forma clara e objetiva. Pois, mesmo quantificando, tais números não expressariam toda a gama de fenômenos e processos que ocorreram na aplicação da pesquisa em sala de aula e os valores finais não refletiriam a realidade vivenciada. Por isso, optamos pela análise qualitativa, para não ficarmos presos a dados estatísticos e gráficos, pois sua flexibilidade permite ao longo da pesquisa um foco amplo e diferente dos métodos utilizados na quantitativa.

Consideramos que o folheto trabalhado é mais uma entre tantas ferramentas de ensino, que direcionam para uma aprendizagem potencialmente efetiva, crítica e significativa, onde os (as) alunos (as) e os (as) professores (as) sejam sujeitos da história e da aprendizagem na busca dos conhecimentos científicos das ciências.

\section{AGRADECIMENTOS}

À Fundação Cearense de Apoio ao Desenvolvimento Científico e Tecnológico - FUNCAP, à Coordenação de Aperfeiçoamento de Pessoal de Nível Superior - CAPES, e à Sociedade Brasileira de Física - SBF, pelo apoio financeiro.

\section{REFERÊNCIAS}

AUSUBEL, D. P. Aquisição e Detenção de Conhecimento: uma perspectiva cognitiva. 1 . ed. Lisboa: Ed. PT, 2003. Tradução Lígia Teopisto.

Borges Neto, H. Sequência FEDATHI: uma proposta pedagógica para o ensino de ciências e matemática. 1. ed. Fortaleza: UFC, 2013.

BRASIL. Lei de diretrizes e bases da educação nacional - LDB Lei no 9394/96. 1996. Disponível em: <http://www.planalto.gov.br/ccivil_03/Leis/L9394. htm>. Acesso em: 12 jun. 2015.

. Parâmetros curriculares nacionais. 1997.

Ministério da Educação. Disponível em: <http: //portal.mec.gov.br/seb/arquivos/pdf/livro01.pdf> Acesso em: 12 jun. 2015.

Parâmetros curriculares nacionais do ensino médio. 2000. Disponível em: <http: //portal.mec.gov.br/seb/arquivos/pdf/blegais.pdf>

Acesso em: 12 jun. 2015.

HEWITT, P. G. Física conceitual. 12. ed. Porto Alegre: Bookman, 2015.

LEMAIRE, R. Fonte de informação e conhecimento, Folclore ou Literatura? O cordel como fenômeno multicultural. 1. ed. Fortaleza: Universidade Federal do Ceará, 2013.

MOREIRA, I. d. C.; MASSARANI, L.; ALMEIDA, C. Cordel e ciência: a ciência em versos populares. 1. ed. Rio de Janeiro: Vieira \& Lent, 2005.

MOREIRA, M. A.; MANSINI, E. F. S. Aprendizagem Significativa: a Teoria de David Ausubel. 1. ed. São Paulo: Moraes, 1982

NOBRE, F. A. S. Os folhetos de cordel como ferramenta didática para o ensino das ciências. In: HOLFMEISTER, D. C. R. (Ed.). Vozes da Cultura Polpular. Leopoldo-RS: Trajetos Editorial, 2015. p. 149-170.

Folhetos de cordel científicos: um catálogo e uma sequência de ensino. 1. ed. São Leopoldo: Trajetos Editorial, 2017.

SAVIANI, D. Pedagogia histórico-crítica: primeiras aproximações. 8. ed. Campinas: Autores Associados, 2003.

SOARES, T. A. A contribuição da Sequência de Ensino Fedathi no processo de Ensino Aprendizagem em física. Dissertação (Instituto de Física / Programa de Pós-Graduação em Ensino de Física (MNPEF)) — Universidade Regional do Cariri URCA, Juazeiro do Norte, 2016.

THIOLLENT, M. Metodologia da pesquisa-ação. 1. ed. São Paulo: Cortez/Autores Associados, 1986. 